which has only recently been received, states that Semple's carbolised sheep vaccine was in use throughout the year, and that 130,821 doses of anti-rabic vaccine were issued. The number of patients treated at the Institute was 545, and 8,056 persons were treated at the centres. The deaths from hydrophobia in these two groups numbered 7 and 60 respectively, giving mortality rates of 1.28 and 0.74 per cent. Hydrophobia is still very prevalent in the Madras Presidency, no less than 661 deaths from this disease being reported during 1931. The remainder of the report gives a complete analysis of the work of the Institute and of results obtained in a series of statistical tables.

\section{Medical Radiology in Canada}

THE promotion of co-operation between radiologists and physicists was discussed at a Conference which met recently at Kingston, Canada, and the formation of an 'associate committee' on medical radiology by the National Research Council of Canada was recommended. The Council was asked to maintain standards of radiation in its laboratories at Ottawa, and to construct portable sub-standards for use in treatment centres, as well as to undertake the distribution of important technical information to Canadian radiologists.

\section{Coventry Public Libraries}

THere are seven public libraries in Coventry which are free to all who live, work or attend school in the city. It is important to have the latest textbooks in engineering and technical science in these libraries. Judging from a booklet entitled "Modern Technology" giving a list of recent books on these subjects, the Libraries Committee has to be con. gratulated on its selection. In the Central Library (Gulson) the standard books of reference, patent specifications, up-to-date trade returns and statistics and trade catalogues can be consulted. Information relating to local and other industries is also supplied on application, which may be made in person, by letter or by telephone.

\section{Announcements}

A Collection of Stoneworts (Charophyta) has been presented to the herbarium of the University of Leeds by the Rev. G. R. Bullock-Webster, who has for many years specialised in this most interesting group of submerged aquatic plants, and who, in collaboration with the late James Groves, wrote a monograph of the family, which was printed by the Ray Society in 1920-24. The collection includes 42 sheets issued as Fascicles $I$ and II, 1924, and 200 additional sheets collected in Great Britain, Ireland, France and Switzerland with a number of authors' proof plates of illustrations.

The Buromin Company of Pittsburg, which has made wide application of molecularly dehydrated phosphates of the alkali metals in water conditioning and washing, has founded an industrial fellowship at the Mellon Institute for the purpose of investigating broadly the properties of these chemicals and of extending their uses in the industries, in medicine, and in the home. Special attention will be accorded to 'Calgon', which is essentially sodium metaphosphate. Dr. Bernard H. Gilmore, who has been selected as the incumbent of this fellowship, started his research programme on June 15 and it is proposed to publish his findings as the researches progress.

WE have received from the Eastman Kodak Co., Rochester, New York, its leaflet "Synthetic Organic Chemicals", vol. 6, No. 4, May, 1933. In addition to a list of thirty-five organic chemicals recently added to stock, the leaflet describes the use of certain reagents for detecting platinum and palladium, with references to the original literature. Half the leaflet is occupied by a short but interesting article on the microscope as an aid to organic chemistry. An 'anti-creep' distillation flask for use with organic liquids which boil at high temperatures is also described and illustrated. The essential feature of the apparatus is the insertion of a comparatively large bulb (1 litre) in the side neck of a modified Claisen flask (3 litres) so that the vapour escapes at right angles to its entrance; the condensate returns to the distillation flask.

WE have recently received vol. 9 of the Japanese Journal of Engineering published by the National Research Council of Japan. This volume contains abstracts, mainly in English, of 28 papers on civil engineering, 12 on naval architecture, 14 on the technology of ordnance, 12 on metallurgy and 141 on various branches of electrical engineering. The original papers were practically all in the Japanese language and were contributed to technical societies or journals in 1929. The abstracts are often of considerable length and enable the reader to follow the work being done in engineering research in Japan. One of the electrical papers deals with the test of a 30,000 k.v.a. asynchronous condenser installed in a Tokyo substation. The condenser was not only the first of its kind made in Japan, but was also the largest of its kind built in the world.

Applications are invited for the following appointments, on or before the dates mentioned:-An assistant master for chemistry, physics and mathematics at the Mining and Technical Institute and Junior Technical Day School, Pontardawe-Director of Education, County Hall, Cardiff (Sept. 5). Assistant lecturer in applied mathematics at University College, Swansea-Registrar (Sept. 5). Assistant marketing officer-Secretary, Ministry of Agriculture and Fisheries, 10 Whitehall Place, London, S.W.1 (Sept. 11). General manager and engineer of Halifax tramways and motor omnibus undertaking -Town Clerk (Sept. 11). Public analyst for the County Borough of Bournemouth-Town Clerk (Sept. 12). A physical chemist and an engineer for service either at the Building Research Station, near Watford, or at the Road Research Laboratory, Harmondsworth-Secretary, Department of Scientific and Industrial Research (Sept. 12). 